\title{
UM EXCURSO SOBRE AS CATEGORIAS EDUCACÃO E TRABALHO NO PENSAMENTO DE ISTVÁN MÉSZÁROS: CONTRIBUIÇÕES PARA A EDUCAÇÃO PROFISSIONAL
}

\author{
Loryne Viana Oliveira \\ E-mail: Loryne@ymail.com \\ Instituto Federal de Educação Ciência e Tecnologia de Brasília \\ DOI: $10.15628 /$ rbept.2020.9827
}

Artigo submetido em: abr./2020 e aceito em: jun./2020

\begin{abstract}
RESUMO
A Educação Profissional situa-se na convergência entre os eixos educação e trabalho. Tal convergência não prescinde de aportes teóricos robustos e posicionados politicamente. Neste sentido, o presente trabalho, de natureza bibliográfica propõe uma reflexão sobre a incidência de fenômenos econômicos e produtivos na educação, considerando o pensamento de István Mészáros, com ênfase no exposto em seu Educação para Além do Capital. O estudo das categorias educação e trabalho nesta obra revela ser impossível uma ação verdadeiramente democrática em uma sociedade que domina hierarquicamente o trabalho e tem regras sobre os sistemas educativos que são impostas por personificações do capital. Apenas uma educação com compromisso revolucionário pode romper com a ordem social vigente e superar a reprodução social e econômica, o que se dará com a reestruturação social, reformulação do ensino, das práticas educativas - que estão imbricadas à dimensão ontológica do trabalho e, por fim, da "própria maneira de ser" dos humanos.
\end{abstract}

Palavras-chave: Educação. Trabalho. Educação Profissional.

\section{AN OVERVIEW ON EDUCATION AND LABOUR IN ISTVÁN MÉSZÁROS'S IDEAS: CONTRIBUTIONS TO VOCATIONAL EDUCATION}

\begin{abstract}
Vocacional education has it's framework structured by two axes: education and labour.This requires sound theorethical basis. In this sense, the present work aims to assess the incidence of economic and productive effects on education, considering the thought of István Mészáros, in his book Education Beyond Capital. The study of the education and labour as categories in this book reveals that it is impossible to have democratic actions in a society that hierarchically dominates labour and has its educational systems ruled over by personifications of capital. Only an education with revolutionary commitment can break with an existing social order and overcome social and economic reproduction. This will only happen if there's a social restructuring, a reform of teaching, of educational practices - which are intertwined with th ontological dimensiono $f$ labour, and finally, of the very way of being of humans. Resumo de inglês de até 10 linhas em espaço simples e letra Arial no tamanho 10.
\end{abstract}

Keywords: Education. Labour. Vocational Education. 


\section{INTRODUÇÃO}

Educação não é uma mercadoria. Era isso que István Mézsaros (19302017) buscava exprimir em seu Educação para Além do Capital, obra escrita por ocasião da conferência de abertura do Fórum Mundial de Educação, ocorrido em 2004, em Porto Alegre. Compreender a translação da educação desde um sentido humano rumo à lógica do capital requer uma análise aprofundada, não apenas do contexto econômico-produtivo, mas, sobretudo, do sentido estruturante da relação entre duas categorias: educação e trabalho.

Remontar este sentido, considerando os modos de pensar a sociedade e apresentando as categorias educação e trabalho, mais especificamente na obra Educação Para Além do Capital, é nosso objetivo no presente texto. O trajeto que cumpre fazer não prescinde de retroagirmos para conceitos outros dos quais parte o filósofo para explicar a dinâmica social sob a égide do capital e para buscar alternativas que nos permitam transcendê-lo.

Para tanto, iniciaremos retomando brevemente em Mészáros (2011), com auxílio de Antunes (1999), a caracterização do sistema de metabolismo do capital e suas mediações. Em seguida, buscaremos compreender as transformações no mundo do trabalho que acompanham a sociedade contemporânea, sobretudo nas formas de materialidade e seus efeitos na subjetividade considerando as formas da sociabilidade humana no contexto da crise do capital e de sua reestruturação constante representadas pelo neoliberalismo e pela acumulação flexível.

Posteriormente, nos detemos na análise da categoria educação, em sua indissociabilidade com a categoria trabalho, representada pelas imagens duais do Homo Faber e Homo Sapiens na educação vocacional e geral. Finalmente, abordamos a sustentabilidade e autogestão, enquanto vias propostas por Mészáros, dando especial atenção às estratégias de transformação e mudança das condições objetivas de reprodução, necessárias para transcender 0 capital.

\section{METABOLISMO SOCIAL DO CAPITAL}

Historicamente, pode-se dizer que o desenvolvimento da produção engendrou a divisão do trabalho e a apropriação privada da terra, tendo por corolário a derrocada do modelo unitário experimentado nas comunidades primitivas. Saviani (2007) explica que foi a apropriação privada da terra, então o principal meio de produção, que gerou a divisão dos homens em classes sociais fundamentais: a classe dos proprietários e a dos não proprietários.

O sistema de metabolismo social do capital origina-se desta divisão social e opera a subordinação estrutural do trabalho ao capital (ANTUNES, 
1999). Mészáros (2011), não atribui a esta relação de submissão do trabalho ao capital um caráter ontológico necessário, mas tão somente um caráter contingencial. O sistema de produção e intercâmbio media as relações entre os seres sociais, formando uma totalidade social estruturada e estabelecida conforme dinâmicas básicas, designadas por Mészáros (2006) como mediações de primeira e segunda ordens.

As mediações de primeira ordem são aquelas formas societais anteriores ao capital, cuja relação entre a produção material era controlada de maneira autossuficiente. Caracterizadas por ter o ser humano como parte da natureza e realizando suas necessidades em intercâmbio com ela, tem comportamentos complexos e guiados por funções primárias de mediação, isentas de hierarquias de dominação e uma atividade biológica consoante com recursos existentes. Nestas formas societais, o processo de trabalho é aquele que interage com a natureza com vistas à produção de bens e conhecimento, e estrutura sistemas de troca para otimização de recursos.

Já as mediações de segunda ordem são aquelas que introduzem elementos fetichizadores de controle social. Caracterizadas pela emergência do sistema de capital, são orientadas para a expansão ilimitada e impelidas pela acumulação. $O$ capital, dinâmico, é uma relação social dinâmica e totalizadora da mediação reprodutiva que subordina todas as funções reprodutivas sociais - as de gênero familiares, as de produção material, as de criação artística - à sua própria expansão. Neste esquema, a organização e divisão do trabalho são sobredeterminadas pelo descolamento entre o valor de uso e valor de troca. Esta organização é descrita também na subsunção formal e real do trabalho ao capital, descrita por Marx.

Entre as condições para a vigência das mediações de segunda ordem destacam-se: a) a separação e alienação entre o trabalhador e os meios de produção, isto é, as funções produtivas e de controle do processo de trabalho social são radicalmente separadas entre aqueles que produzem e aqueles que controlam ${ }^{1}$; b) a imposição dessa condições objetivadas e alienadas sobre os trabalhadores, como um poder separado que exerce o poder sobre eles; c) a personificação do capital como um valor egoísta - com subjetividade e pseudopersonalidade usurpadas -, voltada para 0 atendimento dos imperativos expansionistas do capital; e d) a personificação dos operários como trabalho, o que acarreta uma relação de dependência com o capital

\footnotetext{
1 Esta organização é descrita também na subsunção formal e real do trabalho ao capital, descrita por Marx (1983). Enquanto a subsunção formal tem por base tecnológica a relação ocorrida na oficina artesanal, em que o fator decisivo da produção é o manejo mais ou menos habilidoso do instrumento de trabalho, na subsunção real a base tecnológica é o maquinário, cuja inserção tolhe do trabalhador o controle sobre o conteúdo e ritmo do trabalho. A separação entre os processos de trabalho também é descrita por Fleury e Vargas (1983), bem como por Morgan (1995). Estes autores apresentam a ascensão do taylorismo como princípio de dominação e controle do trabalhador, bem como externam as relações entre o surgimento das máquinas, do pensamento mecânico e da organização burocrática como promovendo a cisão entre as atividades de pensar e fazer, planejar e executar. As atividades brutalizantes impostas ao trabalhador nas grandes empresas capitalistas também é analisado por Braverman (1980).
} 
historicamente dominante, que reduz a identidade do sujeito desse trabalho a suas funções produtivas fragmentárias. Neste sentido, o que se afirma em (a) é que "alienação" não é:

a mediação em geral, mas uma série de mediações de segunda ordem (propriedade privada - intercâmbio divisão do trabalho) uma "mediação da mediação", isto é, uma mediação historicamente específica da automediação ontologicamente fundamental do homem com a natureza. Essa "mediação de segunda ordem" só pode nascer com base na ontologicamente necessária "mediação de primeira ordem" - como a forma específica, alienada, desta última. Mas a própria "mediação de primeira ordem" - a atividade produtiva como tal - é um fator ontológico absoluto da condição humana. (MÉSZÁROS, 2006, p. 78, grifo do autor).

O núcleo constitutivo do sistema de mediação de segunda ordem, dimensões fundamentais do sistema, é a tríade capital, trabalho e Estado. Materialmente interconectadas, é impossível, para Mészáros (2011), eliminálas sem eliminar o conjunto dos elementos que compreende este sistema. Em outras palavras, é impossível emancipar o trabalho sem superar o capital e o Estado:

Devido à inseparabilidade das três dimensões do sistema do capital plenamente articulado - capital, trabalho e Estado -, é inconcebível emancipar o trabalho sem simultaneamente superar o capital e o Estado. Pois, paradoxalmente, o pilar material fundamental de suporte do capital não é o Estado, mas o trabalho em sua contínua dependência estrutural do capital. [...], é quase impossível "esmagar" a dependência estrutural herdada do trabalho em relação ao capital, já que esta dependência é assegurada materialmente pela divisão estrutural hierárquica do trabalho estabelecida. [...] Enquanto as funções controladoras vitais do sociometabolismo não forem efetivamente ocupadas e exercidas autonomamente pelos produtores associados, mas deixadas à autoridade de um pessoal de controle separado (ou seja, um novo tipo de personificação do capital), o próprio trabalho continuará a reproduzir o poder do capital contra si mesmo, mantendo materialmente e dessa forma estendendo a dominação da riqueza alienada sobre a sociedade. (MÉSZÁROS, 2011, p 600-601). 
O trecho citado acima antecipa o caminho indicado pelo autor para a superação do modelo de mediações sociais de segunda ordem. Tal superação é necessária à medida que o sistema de metabolismo social do capital apresenta como defeitos estruturais a separação radical entre a produção e seu controle, bem como a inevitável independência entre produção e consumo - levando ao consumismo -, e por fim, o antagonismo entre produção e circulação. Este último se caracteriza pela insuficiência do capital social total para superar o sistema global, de forma que o trabalho acaba submetido aos alienantes imperativos do sistema global de capital.

O metabolismo social do capital - ao contrário dos metabolismos sociais que the antecederam cujo objetivo primordial era $o$ atendimento de demandas sociais - não se submete a nenhuma tentativa de controle, isto é, nenhuma forma de limitar sua própria expansão. Esta característica o torna ontologicamente incontrolável.

A ausência de unidade dos três elementos supracitados gera antagonismos historicamente moldados, que se manifestam por meio de conflitos fundamentais entre forças sociais hegemônicas diversas. O sistema de mediações imposto pelo capital torna-se um critério de validade generalizável, se aplicando nos mais diversos microcosmos, desde as esferas econômico-financeiras até às economias psíquicas dos sujeitos. Este mesmo sujeito, submetido a esta ordem, tem sua condição de sujeito real da produção degradada por uma relação de objetificação, de redução a um reles "fator material de produção", afetando a prática social na relação entre sujeito e objeto. (MÉSZÁROS, 2011).

Através das personificações do capital - "o dinheiro; a produção para troca; as variedades da formação do Estado pelo capital em seu contexto global; o mercado mundial". (MÉSZÁROS, 2011, p. 71) - obtêm-se este efeito. Tais personificações impõem e mediam seus objetivos com a finalidade de sujeitar o protagonista real do processo produtivo: o sujeito. Ante o exposto, enfatiza o autor:

A ubíqua determinação operativa no sistema do capital é, e continuará a ser, o imperativo da lucratividade. É esta que deve sobrepujar todas as outras considerações, quaisquer que sejam as implicações. Nesse sentido, qualquer coisa que assegure a contínua lucratividade da empresa particular, ipso facto, também a qualifica como empreendimento economicamente viável. Consequentemente, não importa quão absurdamente perdulário possa ser um procedimento produtivo particular; contanto que seu produto possa ser lucrativamente imposto ao mercado, ele deve ser saudado como manifestação correta e apropriada da "economia" capitalista. [...] As práticas obviamente perdulárias aqui envolvidas são plenamente justificadas desde que satisfaçam os critérios capitalistas de "eficiência", "racionalidade" e 
"economia" em virtude da lucratividade comprovada da mercadoria em questão. (MÉSZÁROS, 2011, p. 662).

Assim, considerando as diversas formas societárias de produção, elaboradas e estruturadas ao longo da história, o capital se constitui num amplo sistema de mediações promovidas pela divisão social do trabalho, implicando numa série de determinações de acumulação, a exemplo da formação de monopólios, e multinacionais, extração e transferência de valor para o capital privado, entre outras, evidenciando o desenrolar histórico e constituindo as condições materiais de produção da vida que determinam as relações sociais.

\section{A CATEGORIA EDUCAÇÃO}

A educação encontra-se sobredeterminada pela dinâmica do capital, e foi a este entendimento que buscamos conduzir até aqui nosso texto. Apesar disto, tais sobredeterminações não se inscrevem de modo determinista ou simplista. Na esteira de Marx (1983), para quem circunstâncias produtoras e seres humanos modificados guardam entre si uma relação dialética segundo a qual devem se apreender conforme uma prática transformadora, isto é, não há nada sobreposto à sociedade.

Neste sentido, não há reforma possível para a educação. A única reformulação significativa da educação requer uma transformação substancial no quadro social e nas dinâmicas estruturais do sistema de reprodução vigente. Impregnada pela elisão do conflito, a lógica societária vigente não admite alternativas ao modelo hegemônico, de modo que mesmo "as mais nobres utopias educacionais" (MÉSZÁROS, 2006, p.26) tenham deixado intocado o cerne da questão - o domínio do capital sob a lógica societária -. A despeito das boas intenções dos teóricos da educação cujas críticas rechaçam as manifestações desumanas dos interesses materiais dominantes, os interesses objetivos de classe prevalecem, sugerindo reformas para mitigar os efeitos mais perversos da ordem reprodutiva capitalista.

Pensadores, a exemplo de Robert Owen (1771-1858) e Adam Smith (1723-1790), são incapazes de observar as causas de efeitos sociais "alienantes e desumanizantes do 'poder do dinheiro' e da 'busca do lucro'”. (MÉSZÁROS, 2006, p. 34). Isto se dá em função de que não identificam as contradições e antagonismos subjacentes à ordem do capital, que leva não a uma contradição formal, mas a uma contradição prática. Deste modo, o que se requer para corrigir estes efeitos deve ultrapassar a lógica incorrigível do sistema pelo emprego dos meios disponíveis e indisponíveis - ainda a ser inventados -, de modo consistente, planejado, estratégico.

O fracasso das reformas, portanto, encontra justificativa no fato de ser o capital incorrigível, irreformável por sua própria natureza. Esta perspectiva reformista é nociva por (a) ser identificada com uma perspectiva realista 
propagandeada ad nauseam; (b) ser elitista - uma vez que define educação como atividade intelectual para preservar a ordem vigente contra a anarquia e subversão - ao passo que se pretende democrática; e por fim, (c) excluir a maioria dos sujeitos, já que os considera como objetos que devem permanecer em seus lugares. (MÉSZÁROS, 2006, p. 48).

Enquanto estrutura totalizadora ou o capital mantém seus imperativos sistêmicos estruturais ou é abolido por completo. Historicamente fundados no mito da acumulação primitiva - responsável por naturalizar a ordem social -, a necessidade de trabalhar não atinge a todos igualmente, dado que no nascimento do sistema capitalista, os métodos empregados eram violentos e geradores de iniquidades.

Por séculos, a educação institucionalizada, discute Mészáros (2006), foi subserviente ao propósito do capital, subsidiando o sistema com conhecimentos e qualificação para os sujeitos ${ }^{2}$. Incapaz de enxergar alternativas à gestão da sociedade, seja pela educação do indivíduo, seja pela gestação de novos valores que pudessem escapar à lógica do capital, as instituições de educação se limitaram a abrandar os instrumentos, anteriormente homólogos à violência e brutalidade, não pela incorporação de princípios humanitários, mas em atendimento ao imperativo da eficiência econômica e da eficácia ${ }^{3}$. Tais alterações foram ao encontro das aspirações da reestruturação do capital, por aumentar a intensidade de trabalho, e consequentemente, uma maior produtividade.

Entrementes, as determinações do capital não se cumprem apenas no âmbito educacional formal, mas também nos âmbitos não formais e informais, porquanto estas se integram na totalidade dos processos sociais e não podem ser isoladas, de forma que tais determinações se espraiam em "determinações educacionais gerais da sociedade”. (MÉSZÁROS, 2006, p. 43). Em sentido lato, portanto, educação tem que ver com uma internalização da posição na ordem social hierárquica a ele atribuída, bem como internalização de valores e parâmetros reprodutivos gerais do sistema do capital.

Assim, Mészáros (2006) contraria o papel central da escola e da educação formal na reprodução da lógica societal. Ecoando Freire (2000), nosso autor dirá que "a educação formal não é a força ideologicamente primária que consolida o sistema do capital; tampouco ela é capaz de, por si só, fornecer uma alternativa emancipadora radical" (MÉSZÁROS, 2006, p. 45).

\footnotetext{
2 O leitor encontrará em Noble (1982) uma análise qualificada sobre a tecnologia moderna como um meio para os fins corporativos, sobretudo quando faz uma reconstrução da emergência da engenharia profissional como um passo no processo de institucionalização da pesquisa científica e da invenção. Neste sentido, o engenheiro substitui o prático, que, antes de mais nada, perde seu lugar na divisão de trabalho cada vez mais complexificada pelo desenvolvimento tecnológico e incorporação de sistemas automatizados. Embora suplante o prático, o engenheiro, aponta Noble (1982) ainda requer trabalhadores habilidosos que possam produzir as partes das máquinas de forma a atender às especificações, bem como reuni-las.

${ }^{3}$ Racionalização é palavra de ordem da Administração científica de Taylor. Para Morgan (1985, p. 32), Taylor "fundiu a perspectiva de um engenheiro com a obsessão pelo controle".
} 
Sendo a função da educação formal constituir uma conformidade universal, sob uma perspectiva de Paracelso, enunciada na epígrafe do Educação Para Além do Capital, segundo a qual a aprendizagem é a própria vida, o êxito reside na tomada de consciência do contínuo processo de aprendizagem engendrado na existência dos sujeitos. Mészáros (2006) portanto, coaduna com a centralidade da educação não formal no processo de transformação da ordem social vigente.

Ao contrário do que pode desejar a educação formal, cuja "principal função é agir como um cão de guarda ex-officio e autoritário para induzir a um conformismo generalizado em determinados modos de internalização, de forma a subordiná-lo às exigências da ordem estabelecida" (MÉSZÁROS, 2006, p. 55), a maior parte de nossas vidas é fora de tais quadros institucionais. Os processos de aprendizagem que ocorrem fora destes quadros formam, indelevelmente, nossas subjetividades e identidades.

Se a história nada mais é que uma confluência de consciências, é de se esperar que, ao experimentar uma intensificação nos antagonismos e confrontos hegemônicos entre concepções de mundo, haja uma modificação na relação temporal entre a manutenção do status quo e uma mudança social significativa. $\mathrm{O}$ dito ponto arquimediano a partir do qual tais contradições da ordem social se revelarão inteligíveis e superáveis nos conduz à próxima categoria de análise: 0 trabalho.

\section{CATEGORIA TRABALHO}

O significado de trabalho, segundo Mészáros (2005), se relaciona, conforme a organização do metabolismo social, em duas partes, o trabalho segundo as mediações de primeira ordem e o trabalho no contexto das mediações de segunda ordem:

O trabalho é considerado tanto em sua acepção geral - como "atividade produtiva": a determinação ontológica fundamental da "humanidade" ("menschliches Dasein", isto é, o modo realmente humano de existência) - como em sua acepção particular, na forma da "divisão do trabalho" capitalista. É nesta forma - a atividade estruturada em moldes capitalistas - que o "trabalho" é a base de toda a alienação. (MÉSZÁROS, 2006, p. 78, grifo original).

A mediação de primeira ordem, homóloga em Marx (2010), é a atividade produtiva, ou seja, o trabalho. Esta categoria assume um caráter ontológico absoluto, capaz de caracterizar o próprio modo de existência humano, expresso nas indispensáveis transformações da natureza realizadas pela atividade produtiva distintivas da nossa espécie. Ao passo que as ditas 
mediações de segunda ordem supõem a "divisão do trabalho, propriedade privada, intercâmbio" (MÉSZÁROS, 2006, p. 78), constituem formas alienadas historicamente constituídas.

Ou seja, é necessária a distinção entre dois trabalhos: de um lado temos o absoluto, a atividade humana produtiva em geral, enquanto fator ontológico, e, do lado oposto, encontramos sua forma alienada e historicamente específica, portanto, relativa, o trabalho assalariado. Esta distinção é fundamental já que, sem ela incorremos na suposição de uma atividade unitária, homogênea, o que leva à impossibilidade de sua transcendência e superação práticas. (MÉSZÁROS, 2006).

Portanto, em um excurso sobre a centralidade do trabalho, identificamos na categoria a relação entre práxis laborativa ou interativa e intersubjetiva, conceituação de aspiração lukasiana, a qual constrói uma ontologia baseada no trabalho como protoforma ${ }^{4}$ da práxis social, já que a linguagem, a ética, a política, a filosofia, e a arte encontram sua origem no ato laborativo, na sociabilidade, primeira divisão do trabalho.

Para Lukács (1980), a causalidade dada pela materialidade, desencadeadora do ato teleológico, é deflagrada pela necessidade humana e social, ou seja, a atividade humana se torna autogovernada, configurando 0 espaço da liberdade subjacente à decisão entre alternativas diversas. Logo, 0 trabalho configura a passagem da espontaneidade do instinto para 0 comportamento consciente, e é a necessidade de convencer outros seres sociais a realizar determinado ato teleológico que leva ao surgimento da práxis interativa.

Na perspectiva pressuposta por Mészáros (2006), portanto, o trabalho sob as condições totalizantes do capital é incompatível com o trabalho em sua perspectiva ontológica. É dizer: o trabalho que estrutura o capital desestrutura a humanidade e o trabalho que estrutura a humanidade é incompatível com o sentido de trabalho que o capital impõe. (ANTUNES, 1999).

O trabalho, portanto, não desempenha, na ordem metabólica vigente, a função principal que regula necessidades vitais da sociedade. Ele segue a organização hierarquizada da produção e das relações sociais que sustentam o controle do capital, isto é, a formação vertical do trabalho torna possível o metabolismo social que assegura a perpetuação do capital. Isto é: as mediações de segunda ordem subordinam o trabalho à lógica do capital.

Sendo assim, o processo de alienação se torna condição sine qua non para a manutenção da ordem social e reprodutiva do capitalismo. Um dos efeitos consistem na redução, por parte dos trabalhadores, de suas identidades em decorrência do decurso do trabalho - alienado -, impedindo, assim, o pleno desenvolvimento do sujeito, diretamente vinculados, de certa maneira, à forma de arranjo social da produção, ou seja, da divisão social do trabalho.

\footnotetext{
${ }^{4}$ Refere-se à forma originária do ser social.
} 
Mészáros (2006) segue para lembrar-nos que todas os processos de alienação têm sua origem comum na alienação do trabalho como um processo de autoalienação escravizante. Justamente por tratar-se de um processo histórico - portanto contingente, que não deve ser mistificado como essencial, metafísico, essencial, imutável ou necessário - é superável pelo próprio trabalho. Portanto, nas palavras de nosso autor, pelo próprio trabalho é "possível superar a alienação com uma reestruturação radical das nossas condições de existência há muito estabelecidas e, por conseguinte, de 'toda nossa maneira de ser". (MÉSZÁROS, 2006, p. 60).

Tal processo de superação não deve ater-se à mera negação, muito embora num primeiro estágio a negação seja necessária, pois as formas de negação sempre permanecem pautadas pelo seu próprio objeto. Ou seja, mesmo que seja inescapável, a negação deve ser "orientada pelo alvo global da transformação social visada" (MÉSZÁROS, 2006, p. 61), o que exige uma antecipação positiva de um novo metabolismo social. Tal processo portanto, une as duas categorias em tela, estudadas neste texto. A tal processo Mézsáros (2006) dá o nome de transcendência positiva da autoalienação do trabalho, objeto de nossa análise a seguir.

\section{INTERRELAÇÃO ENTRE EDUCAÇÃO E TRABALHO: A TRANSCENDÊNCIA POSITIVA DA AUTOALIENAÇÃO DO TRABALHO}

A tarefa proposta por Mészáros (2006) é maior que a mera negação do capitalismo, o que não prescinde de uma mudança completa da maneira de ser dos seres humanos. Aí reside a dimensão do que está para além do capital: é a ordem que - ao invés de uma proposta reformista que enfoca os efeitos do sistema dominante sem ameaçar sua base causal - subverte 0 sociometabolismo de forma a autossustentável. (MÉSZÁROS, 2006, p. 62).

Tendo em vista o objetivo de transformar qualitativamente as condições objetivas da reprodução social, Mészáros afirma (a) a necessidade de reconquistar o controle do capital enquanto estrutura, e não enquanto instância personificada do sistema capitalista e (b) transformar progressivamente as consciências. Em (b) fica evidente a relação entre educação e trabalho: cabe à educação elaborar tanto "estratégias apropriadas e adequadas para mudar as condições objetivas de reprodução, como para automudança consciente dos indivíduos chamados a concretizar a criação de uma ordem social metabólica radicalmente diferente". (MÉSZÁROS, 2006, p. 65).

Nesta tarefa, a educação é protagonista e soberana, e acompanhando Marx, Mészáros (2005, p. 65) irá atribuir a ela o papel de "efetiva transcendência da autoalienação do trabalho". Daí a confluência entre trabalho e educação: este intento requer a "universalização da educação e a universalização do trabalho como atividade humana autorrealizadora". 
Esta ideia não é inovadora, porquanto Paracelso, um dos autores da epígrafe do livro já apresentava um modelo de difusão da aprendizagem pelo trabalho e expropriação da fortuna dos ricos ociosos. Ainda contra o melhor bom-senso ou ceticismo, Mészáros (2006), ao citar o exemplo cubano de universalização da educação e do trabalho, nos provoca a pensar que não há de se esperar a conjuntura mais favorável para perseguição deste objetivo emancipador.

Historicamente temos razões para o fracasso sucessivo da implantação deste caminho. O capital foi demasiado bem sucedido em instituir jornadas de trabalho extenuantes, que nos desumanizam e tomam a maior parte do tempo de vida dos seres humanos, de forma a controlar totalmente as funções de reprodução sociometabólica. Destarte, "não só o controle do trabalho estruturalmente subordinado, mas também a dimensão do controle da educação tinha de ser mantidos num compartimento separado, sob o domínio da personificação do capital na nossa época". (MÉSZÁROS, 2006, p. 68).

Haja vista o requisito prévio de uma igualdade substancial - em contraposição à frequentemente anulada igualdade formal -, o preceito de universalização da educação e do trabalho não se realiza, o que pode ser historicamente observado por meio da dualidade da educação e do próprio trabalho. Mészáros (2006) oferece enquanto instâncias de seu raciocínio um trecho do consagrado pai da administração, Frederick Taylor (1856-1915) no qual afirma que quanto menos intelectualmente sofisticado o trabalhador for, quanto mais adequado será para o preenchimento de seu posto.

Alternativamente Mészáros (2006) propõe a sustentabilidade, definida por ele como sendo a única espécie factível de autocontrole, ou seja, o "controle consciente do processo de reprodução metabólica social por parte de produtores livremente associados" (MÉSZÁROS, 2006, p. 72). Tal ativação depende da educação em sentido lato, capaz de oferecer uma alternativa concreta por meio da automediação, autocontrole e autorrealização. Dito de outra forma, os indivíduos associados não precisam ser governados pela lógica do capital - imposta através da alienação de mediações de segunda ordem -, mas sim, aprender a governar-se a si próprios, valendo-se da liberdade substantiva e da igualdade.

Esta alternativa não prescinde ainda de valores que acompanhem a real necessidade dos indivíduos, revertendo a estrutura de "apetites totalmente artificiais e reificados da acumulação lucrativa do capital". (MÉSZÁROS, 2006, p. 73). Esta forma alternativa permitiria instituir prioridades e definir necessidades reais, avessas ao atual círculo vicioso de desperdício e escassez e uma contraproducente acumulação - oriundos da deficiência estrutural do capital -, em que nos encontramos.

Para tanto, retornamos no apelo por trás de Educação Para Além do Capital, é urgente a autoeducação de iguais e autogestão da ordem social, cujo pano de fundo é uma concepção alargada de educação, como afirma a epígrafe do livro "aprendizagem é nossa própria vida". 
A propalada autogestão simboliza um empreendimento progressivo e a mudança e é suportada por práticas educativas que "habilitem o indivíduo a realizar estas funções [vitais do processo metabólico social] na medida em que sejam redefinidas por eles próprios de acordo com os requisitos em mudança dos quais eles são agentes ativos". (MÉSZÁROS, 2006, p. 74). A educação enquanto categoria na obra que estamos estudando é, portanto, declaradamente uma educação continuada, não formal e informal, não vocacional - pois não utilitarista, reducionista e instrumental -, e não geral considerando que a educação geral trata indivíduos de forma paternalista ao distribuir habilidades para o pensamento.

A dualidade educação geral e educação vocacional são, portanto, rejeitadas enquanto agentes da cisão entre as dimensões prática e estratégica. Enquanto na educação geral predomina um caráter condescendente do conhecimento, como se este estivesse suspenso da realidade, desvinculado de sua dimensão mundana e da necessidade premente de reprodução das condições objetivas de sobrevivência, nos termos de Mészáros (2005), a educação vocacional, impede o sujeito de acessar o conhecimento e agir sobre ele, pois não envolve o domínio de códigos técnicos, apenas sua reprodução.

Esta linha argumentativa, da recusa da dualidade educacional possui ascendência gramsciana, uma vez que reconhece a possibilidade de que todo homem seja um intelectual que "partilha uma concepção do mundo, tem uma linha consciente de conduta moral e, portanto contribui para manter ou mudar a concepção de mundo, isto é, para estimular novas formas de pensamento" (GRAMSCI apud MÉSZÁROS, 2006, p. 49). Em outras palavras, deve-se abandonar a separação entre homo sapiens e homo faber (GRAMSCI, 2013), e esta é a única via realmente democrática para a educação, enquanto aduz ao fato de que não há separação entre a dimensão intelectual e o processo da ação, da atividade, do trabalho:

\begin{abstract}
Primeiro ele insiste em que todo ser humano contribui, de uma forma ou de outra, para formação de uma concepção de mundo predominante. Em segundo lugar, ele assinala que tal contribuição pode cair nas categorias contrastantes da "manutenção" e da "mudança". Pode não ser apenas uma ou outra, mas ambas, simultaneamente. Qual das duas é mais acentuada, e em que grau, isso obviamente dependerá da forma como as forças sociais conflitantes se confrontam e defendem seus interesses alternativos importantes. (MÉSZÁROS, 2006, p. 50).
\end{abstract}

Como cada homem se desenvolve para além do seu trabalho e para além de sua jornada na educação formal, a transformação da realidade é possível. Para isso, é proposta a educação continuada, a qual é: 
[...] inseparável da prática significativa da autogestão. Ela é parte integral desta última, como representação no início da fase de formação na vida dos indivíduos, e, por outro lado, no sentido de permitir um efetivo feedback dos indivíduos educacionalmente enriquecidos com suas necessidades mudando corretamente e redefinidas de modo equitativo, para a determinação global dos princípios orientadores objetivos da sociedade. (MÉSZÁROS, 2006, p. 75).

Finalmente, a tarefa da educação, por assim dizer, é, num movimento dialético, realizar duas transformações inseparáveis: uma transformação ampla e uma transformação emancipadora. A articulação é calibrada reciprocamente, pautada pelas próprias necessidades. Para realizar ambas as transformações, deve-se cumprir outro movimento dialético, agora para combinar tarefas imediatas e estruturas estratégicas: se a estrutura estratégica representa a síntese global das tarefas imediatas, esta derradeira não pode perder de vista a anterior. Nas palavras de nosso autor:

Ou ambas [transformações] têm êxito e se sustentam, ou fracassam juntas. Cabe a nós todos - todos, porque sabemos muito bem que "os educadores também têm de ser educados" - mantê-la de pé, e não deixá-las cair. As apostas são elevadas demais para que se admita a hipótese de fracasso. (MÉSZÁROS, 2006, p. 77).

A tarefa que cumpre realizarmos é então a tarefa de uma transformação qualitativa urgente, necessária, capaz de emancipar de forma ampla a todos. Sem tal transformação, os caminhos para os quais se insinua o sistema ameaça não apenas alcançar uma deficiência de recursos econômicos, mas as próprias condições elementares da sobrevivência de nossa espécie.

\section{CONSIDERAÇÕES FINAIS}

Nos termos estritos e totalizantes do sistema de mediações de segunda ordem, torna-se impossível uma ação verdadeiramente democrática em uma sociedade que domina hierarquicamente o trabalho e tem regras impostas por representantes e tomadores de decisão do capital transnacional sobre como os sistemas educativos devem orientar-se.

Com efeito, a educação não se explica em si nem "funciona suspensa no ar", daí a necessidade da compreensão histórica das expressões concretas de uma determinada cultura. Isto posto, a educação fornece mecanismos e possibilidades reais para alterar essas relações, tornando-as sustentáveis, 
alcançando a capacidade de controle consciente da reprodução de um novo metabolismo social, orientada pela livre associação dos trabalhadores, portanto, qualitativamente superior. Vale lembrar, entretanto, que a educação não se caracteriza como fator determinante, mas sim um fator determinado, e, justamente por isso, exerce ação integrante na transformação social.

A categoria educação na referida obra é tributária da dimensão política do processo que representa. A associação consciente dos indivíduos é intermediada por práticas educativas, que habilitam o sujeito a objetivar as ações transformadoras das relações reprodutivas do metabolismo social. Nesse sentido, a educação se torna continuada e, por conseguinte, se impõe como uma prática que norteia ou pode nortear uma conjuntura social para além do capital. A discussão teórica realizada nos habilita concluir que uma sociedade fundada na lógica do capital traz consigo o conflito de interesses entre classes e a dita educação para além do capital busca a superação de tal sistema mundial. Apenas uma educação com compromisso revolucionário pode romper com a ordem social vigente e superar a reprodução social e econômica, acompanhada da reestruturação social, reformulação do ensino e de práticas educativas e dos demais estratos sociais.

Se a "a educação formal não é a força ideologicamente primária que consolida o sistema do capital" e é incapaz de sozinha, "fornecer uma alternativa emancipadora radical" (MÉSZÁROS, 2006, p. 45), cumpre lembrar o papel das teorias. Compreendemos que este é o principal contributo da presente reflexão à Educação Profissional: um arcabouço teórico robusto. Este é o primeiro passo para que teorias, nas palavras de Vázquez (1977, p. 206), "saiam de si mesmas", para que "sejam assimiladas". A educação das consciências, a que tanto aludem István Mészáros, Paulo Freire e Sánchez Vázquez é sim, contínua, popular, não formal. Isto não significa que a educação formal e suas instituições não sejam loci de potencialização desta educação.

Teorias estruturam as ações, teorias podem ser potentes e produzir resultados concretos, mas mais importante: teorias mediam o essencial trabalho de "educação das consciências, de organização dos meios materiais e planos concretos de ação: tudo isso como passagem indispensável para desenvolver ações reais, efetivas". (VÁZQUEZ, 1977, p. 206). Neste sentido, as contribuições das categorias Educação e Trabalho em Mészáros (2005; 2006; 2011) para a Educação Profissional não se restringem à compreensão de que as condições objetivas para a transformação da realidade devem ir além de reformismos. Aponta, sobretudo, para o fato de que a práxis da educação profissional deve transcender 0 instrumentalismo e a orientação mercadológica, deve ser reestruturada pela superação da dualidade entre o fazer e o pensar (GRAMSCI, 2013), e deve incorporar "a presença organizada das classes sociais populares na luta em favor da transformação democrática da sociedade, no sentido da superação das injustiças sociais". (FREIRE, 2001, p. 49). 


\section{REFERÊNCIAS}

ANTUNES, R. Os sentidos do trabalho: ensaio sobre a afirmação e a negação do trabalho. São Paulo: Boitempo, 1999.

BRAVERMAN, H. Trabalho e Capital Monopolista: a degradação do trabalho no séc. XX. Rio de Janeiro: Zahar, 1980.

FLEURY, A.; VARGAS, N. Organização do Trabalho. São Paulo: Atlas, 1983.

FREIRE, P. Pedagogia da indignação: cartas pedagógicas e outros escritos. São Paulo: Editora UNESP, 2000.

FREIRE, P. Política e educação: ensaios. São Paulo: Cortez, 2001.

GRAMSCI, A. A formação dos intelectuais. Rio de Janeiro: Achiamé, 2013. LUKÁCS. G. The Ontology of Social Being: Labour. Londres: Merlin Press, 1980.

MARX, K. Manuscritos econômico-filosóficos. São Paulo: Boitempo, 2010. MARX, K. O Capital. São Paulo: Abril Cultural, 1983.

MÉSZÁROS, I. A educação para além do capital. São Paulo: Boitempo, 2005.

MÉSZÁROS, I. A teoria da alienação em Marx. São Paulo: Boitempo, 2006. MÉSZÁROS, I. Para além do capital: rumo a uma teoria da transição. São Paulo: Boitempo, 2011.

MORGAN, G. Imagens da Organização. São Paulo: Atlas, 1995.

SAVIANI, D. Trabalho e educação: fundamentos ontológicos e históricos.

Rev. Bras. Educ., Rio de Janeiro, v. 12, n. 34, p. 152-165, abr. 2007.

Disponível em: < https://www.scielo.br/pdf/rbedu/v12n34/a12v1234.pdf>. Acesso em: 01 jun. 2020.

VÁZQUEZ, A.S. Filosofia da Práxis. Rio de Janeiro: Paz e Terra, 1977. 